\title{
OPEN
}

\section{Author Correction: Cytotoxic unsaturated electrophilic compounds commonly target the ubiquitin proteasome system}

Karthik Selvaraju, Arjan Mofers, Paola Pellegrini, Johannes Salomonsson (D), Alexandra Ahlner, Vivian Morad, Ellin-Kristina Hillert $\mathbb{D}$, Belen Espinosa, Elias S. J. Arnér $\mathbb{B}$, Lasse Jensen, Jonas Malmström, Maria V. Turkina, Padraig D'Arcy, Michael A. Walters $\mathbb{D}$, Maria Sunnerhagen \& Stig Linder

Correction to: Scientific Reports https://doi.org/10.1038/s41598-019-46168-x, published online 08 July 2019

This Article contains an error in Figure 8d, where the incorrect brightfield image is shown for the DMSO control embryo at 0 hours. The correct brightfield image appears below.

The conclusions of the Article are unaffected by these changes.

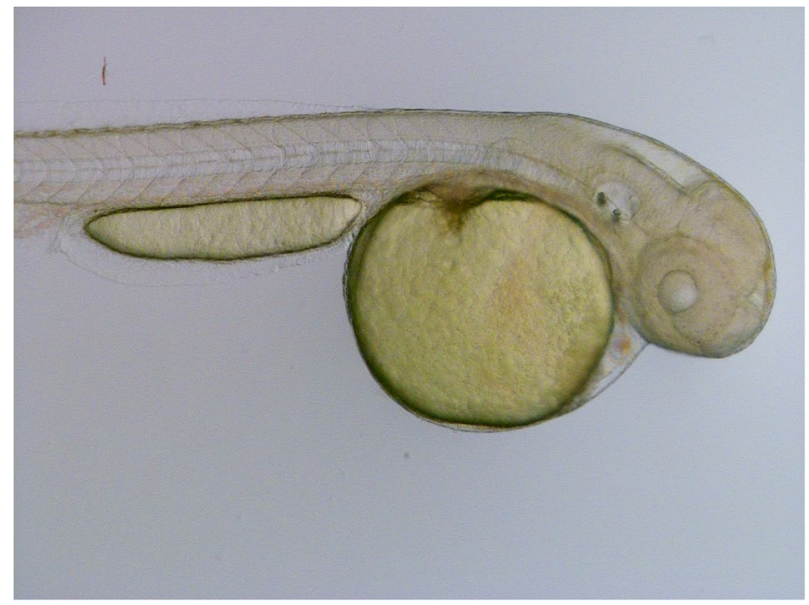

Figure 1.

(i) Open Access This article is licensed under a Creative Commons Attribution 4.0 International License, which permits use, sharing, adaptation, distribution and reproduction in any medium or format, as long as you give appropriate credit to the original author(s) and the source, provide a link to the Creative Commons license, and indicate if changes were made. The images or other third party material in this article are included in the article's Creative Commons license, unless indicated otherwise in a credit line to the material. If material is not included in the article's Creative Commons license and your intended use is not permitted by statutory regulation or exceeds the permitted use, you will need to obtain permission directly from the copyright holder. To view a copy of this license, visit http://creativecommons.org/licenses/by/4.0/. 